\title{
Plant-hyphomycete interactions in lowland central Burma
}

\author{
M. M. Thaung
}

Received: 22 August 2011 / Accepted: 9 September 2011 /Published online: 4 October 2011

(C) Australasian Plant Pathology Society Inc. 2011

\begin{abstract}
Some 470 specimens of hyphomycetes reported earlier from about 85 plant families of lowland central Burma were reviewed for pattern and process of fungus-host associations in the field. Cercospora/Allies, Alternaria/Nimbya, Fusarium, Bipolaris and Curvularia associated more frequently as foliar pathogens with larger families like the Asteraceae, Fabaceae and Poaceae than with medium to smaller families notably the Cucurbitaceae, Euphorbiaceae, Lamiaceae, Malvaceae, Solanaceae, and Zingiberaceae. Plant-fungus interactions being inferred from these associations, it is hypothesized, using collection frequency analyses, that interactions (I) varied jointly with the fungus (F) and the host plant $(\mathrm{P})$ family as per symbolic representation: $\mathrm{I}=\mathrm{F} \times \mathrm{P}=\mathrm{FP}$.
\end{abstract}

Keywords Alternarioses - Cercosporioses · Fusarioses · Multicyclic diseases $\cdot$ Phytopathogens

This note presents fungus-host associations between foliar hyphomycetes and wild plants in natural vegetation of lowland central Burma. The objective was to discover pattern and process of associations in the field, and to observe that being the joint end products of plant-fungus interactions in their trophic encounters, the associations reflect and represent the interactions. The study also aimed to develop a hypothesis of plant-fungus interac-

M. M. Thaung $(\bowtie)$

Natural History Museum of Los Angeles County,

900 Exposition Blvd,

Los Angeles, CA 90007, USA

e-mail: mmthaung@verizon.net tions (I) following a pattern of joint variation between plant family $(\mathrm{P})$ and fungus $(\mathrm{F})$ genus, which is expressed as: $\mathrm{I}=\mathrm{F} \times \mathrm{P}=\mathrm{FP}$.

Lowland central Burma is a dry-zone biome in a tropical dry to wet monsoon ecosystem between latitudes $22^{\circ} 34^{\prime} \mathrm{N} 95^{\circ} 42^{\prime} \mathrm{E}$ and $18^{\circ} 48^{\prime} \mathrm{N} 95^{\circ} 13^{\prime} \mathrm{E}$. It is crisscrossed with mostly rain-fed agroecozones of legumes, grains, fibers, sugarcane and vegetable crops, thus supplying a vast source and a broad base for variable lifestyles of fungal communities. The high temperatures and low precipitations are the only major ecological constraints.

Cercospora, Alternaria and Fusarium species have been reported applying a number of morphologic and physiologic characters, melanin, phytotoxins, pathotypes, reactive oxygen species, living strategies, etc. for their success as foliar pathogens of cultivated plants (Daub and Chung 2007, 2009; Daub and Ehrenshaft 2000; Gessler et al. 2007; Heiser et al. 1998; Jacobson 2000; Jacobson et al. 1995; Ji et al. 2006; Kawamura et al. 1997, 1999; Laemmlen 2001; Nishimura and Kohmoto 1983; Rotem 1994; Thomma 2003). They cause multicyclic diseases generally referred to as alternarioses, cercosporioses, and fusarioses. However, their performance as such on wild plants in nature is hitherto unknown or unavailable. Likewise, their trophic interaction has never been recorded as a process of joint variation with plant, resulting in association identifiable by signs or symptoms of a pathologic condition.

Materials collected randomly and intermittently by Thaung $(1984,2008)$ from plants over a period of 5 consecutive years and on deposits at Herb. IMI and UC (= LAM) were revisited. Specimens of 12 common hyphomycete genera and their host plant families were selected and analyzed as 
Table 1 A 5-year summary of plant-hyphomycete interactions/associations in lowland central Burma

\begin{tabular}{|c|c|c|c|c|c|c|c|c|c|c|c|c|c|c|}
\hline Fungus genus & $\mathrm{Sp}$ & Spm & $\mathrm{PF}$ & A & $\mathrm{F}$ & $\mathrm{P}$ & $\mathrm{C}$ & $\mathrm{E}$ & $\mathrm{L}$ & $\mathrm{M}$ & $\mathrm{S}$ & $\mathrm{B}$ & $\mathrm{Z}$ & $\mathrm{O}$ \\
\hline 1. Cercospora + Allies & 207 & 244 & 69 & 28 & 37 & 13 & 8 & 8 & 8 & 8 & 8 & 4 & & 122 \\
\hline 2. Alternaria/Nimbya & $45+3$ & 84 & 39 & 10 & 4 & 5 & 4 & 2 & 1 & 3 & 7 & 9 & 1 & 38 \\
\hline 3. Fusarium & 15 & 17 & 10 & 1 & 3 & 4 & 1 & & & 1 & & & & 7 \\
\hline 4. Bipolaris & 9 & 15 & 6 & & 1 & 10 & & 1 & & & & & & 3 \\
\hline 5. Curvularia & 12 & 36 & 19 & 2 & 3 & 10 & 1 & 1 & 1 & & & & 1 & 17 \\
\hline 6. Corynespora & 1 & 22 & 15 & & 3 & 1 & & 3 & 4 & 1 & 1 & & & 9 \\
\hline 7. Drechslera & 10 & 10 & 6 & & & 4 & & 2 & 1 & & & & & 3 \\
\hline 8. Exserohilum & 1 & 1 & 1 & & & 1 & & & & & & & & 0 \\
\hline 9. Periconia & 4 & 16 & 12 & & 2 & 1 & & 1 & & 1 & 2 & 1 & & 8 \\
\hline 10. Pyricularia & 3 & 11 & 3 & & & 9 & & & & & & & 1 & 1 \\
\hline 11. Tetraploa & 1 & 11 & 6 & & & 3 & & & & & & & 1 & 7 \\
\hline 12. Zygosporium & 5 & 6 & 5 & & & & & & & & & & & 6 \\
\hline Total & & 473 & & 41 & 53 & 61 & 14 & 18 & 15 & 14 & 18 & 14 & 4 & 221 \\
\hline
\end{tabular}

$S p$ fungus spp, $S p m$ specimen, $P F$ host plant family, $A$ Asteraceae, $F$ Fabaceae, $P$ Poaceae, $C$ Cucurbitaceae, $E$ Euphorbiaceae, $L$ Lamiaceae, $M$ Malvaceae, $S$ Solanaceae, $B$ Brassicaceae, $Z$ Zingiberaceae

$O=75$ other families. Specimen total $=473$. Host family total $=10$ above $+75=85$

follows for their composite, cumulative, and joint-variation interaction frequencies:

Example: (1) Fungus $A, B$, and $C$ interact with a plant family $P$ for a total of 2,3 and 4 times, respectively.

Hence, their composite interaction frequencies on $P$ are 2, 3 and 4 for $A, B$, and $C$ individually and respectively.

And, the cumulative interaction frequency of $P$ is: $2+3+4=9$ collectively for all of $(A$, $B$, and $C$ ) together.

Example: (2) Fungus $A$ and $B$ interact with $X$ and $Y$ numbers of plant families for total frequencies of $R$ and $T$ respectively. Hence, their joint-variation interaction is: $R$ happens and changes as and when $A$ and $X$ change and interact. So is the same for $T$ varying with $B$ and $Y$. The symbolic expression of this relationship is: $\mathrm{I}=\mathrm{F} \times \mathrm{P}=\mathrm{FP}$.

Results are summarized in a matrix from taxonomic and pathologic reassessment of 473 hyphomycete specimens associated with 85 plant families (Table 1). The summary serves as the database for this investigation. The composite (Table 2, Fig. 1) and the cumulative (Table 2, Fig. 2) interactions of 10 fungal groups are provided for a range of 12 host plant families. The joint-variation in interactions is indicated between the fungus populations and their host plant families by their joint end products, that is, their total
Table 2 Composite and cumulative distributions of planthyphomycete interactions in central Burma

Ap Apocynaceae, As Asclepiadaceae, Ast Asteraceae, $B$ Brassicaceae, $C$ Cucurbitaceae, $E$

Euphorbiaceae, $F$ Fabaceae, $L$ Lamiaceae, $M$ Malvaceae, $P$ Poaceae, $S$ Solanaceae, $Z$ Zingiberaceae

${ }^{\mathrm{a} C o l u m n}$ total $=$ cumulative, and Column series under host family $=$ composite

\begin{tabular}{lcccccccccccrr}
\hline Fungus genus & Ap & As & Ast & B & C & E & F & L & M & P & S & Z & Total \\
\hline 1. Alternaria/Nimbya & 1 & 1 & 10 & 9 & 4 & 2 & 4 & 1 & 3 & 5 & 7 & 1 & 48 \\
2. Bipolaris & 1 & & & & & 1 & 1 & & & 10 & & & 13 \\
3. Cercospora+Allies & 6 & 5 & 28 & 4 & 8 & 8 & 37 & 8 & 8 & 13 & 8 & 7 & 140 \\
4. Corynespora & 1 & 1 & & & & 3 & 3 & 4 & 1 & 1 & 1 & & 15 \\
5. Curvularia & & 1 & 2 & & 1 & 1 & 3 & 1 & & 10 & & 1 & 20 \\
6. Drechslera & & & & & & 2 & & 1 & & 4 & & & 7 \\
7. Fusarium & & & 1 & & 1 & & 3 & & 1 & 4 & & & 10 \\
8. Periconia & 1 & & & 1 & & 1 & 2 & & 1 & 1 & 2 & & 9 \\
9. Pyricularia & & & & & & & & & & 9 & & 1 & 10 \\
10. Tetraploa & & & & & & & & & & 3 & & 1 & 4 \\
a Cumulative & 10 & 8 & 41 & 14 & 14 & 18 & 53 & 15 & 14 & 60 & 18 & 11 & 276 \\
\hline
\end{tabular}




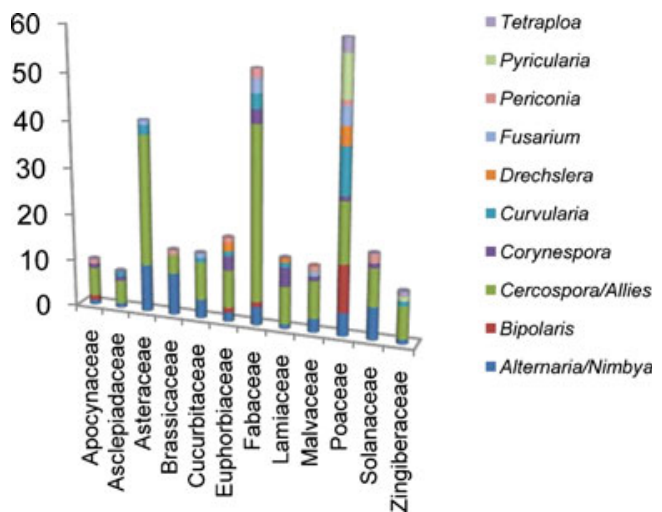

Fig. 1 Composite distributions of interactions by plant families

interaction frequencies (Table 3, Fig. 3). Hence, the joint variation pattern: $\mathrm{I}=\mathrm{F} \times \mathrm{P}=\mathrm{FP}$.

The composite distribution shows relative association frequencies of Alternaria/Nimbya, Bipolaris, Cercosporal Allies, Corynespora, Curvularia, Drechslera, Fusarium, Periconia, Pyricularia, Tetraploa, and Zygosporium for each plant family (Fig. 1). The cumulative distribution displays individual sum totals of these frequencies for each of the plant families: the Asteraceae, Cucurbitaceae, Euphorbiaceae, Fabaceae, Lamiaceae, Malvaceae, Poaceae, Solanaceae and Zingiberaceae (Fig. 2). These fungi, their host plant families and their total interaction frequencies together manifest a pattern of joint variation in the association or interaction process (Fig. 3).

The plant-fungus interaction frequencies are high especially when both interactants are greatly diversified and widely distributed as, for instance, Cercospora/Allies, Alternaria/Nimbya, and Fusarium on the Asteraceae, Fabaceae, and Poaceae. However, they are low for the same fungi when the other interactant is relatively small in size, limited in diversity and distribution as, for example, the Cucurbitaceae, Euphorbiaceae, Lamiaceae, Malvaceae, Solanaceae and Zingiberaceae (Fig. 1). The Asteraceae, Fabaceae and Poaceae peak out individually in their

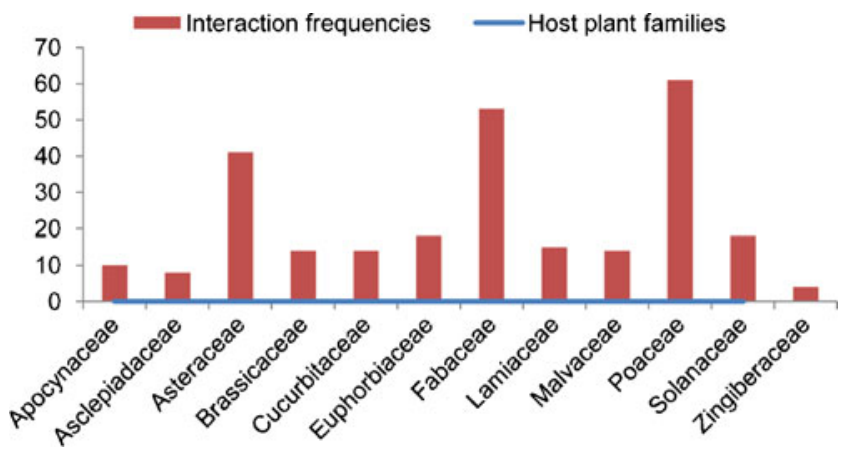

Fig. 2 Cumulative distributions of interactions by plant families
Table 3 Plant-fungus interactions of common hyphomycetes in lowland central Burma

\begin{tabular}{lrcc}
\hline Fungus genus & Fungus species & Plant family & $\begin{array}{l}\text { Interaction } \\
\text { frequencies }\end{array}$ \\
\hline 1. Alternaria/Nimbya & $45+3$ & 39 & 84 \\
2. Bipolaris & 9 & 6 & 15 \\
3. Cercospora+Allies & 207 & 69 & 244 \\
4. Corynespora & 1 & 15 & 22 \\
5. Curvularia & 12 & 19 & 36 \\
6. Drechslera & 10 & 6 & 10 \\
7. Fusarium & 15 & 10 & 17 \\
8. Periconia & 4 & 12 & 16 \\
9. Pyricularia & 3 & 3 & 11 \\
10. Tetraploa & 1 & 6 & 11 \\
11. Zygosporium & 5 & 5 & 6
\end{tabular}

cumulative interactions with all ten hyphomycete groups (Fig. 2).

The Poaceae is noteworthy for its immense interactivity with more hyphomycetes than any other plant family in Burma. Being among the top three largest plant families in the world with herbaceous structures, the Asteraceae, Fabaceae and Poaceae dominate as the most common interactive host plants for many of the fungi in the ecosystem.

Further analyses of interaction frequencies also find Alternaria/Nimbya, Bipolaris, Cercospora/Allies, Corynespora, Curvularia, Drechslera, Fusarium, Periconia, Pyricularia, Tetraploa, and Zygosporium varying jointly with their host plant families (Fig. 3). All available field data thus support the hypothesis of plant-fungus associations being reflections of their trophic interactions (I) varying jointly with the fungus $(\mathrm{F})$ and the host plant $(\mathrm{P})$ family.

It is projected that this trend of plant-hyphomycete interactions will continue in lowland central Burma until and unless impacted by climate and landscape changes especially agriculture.

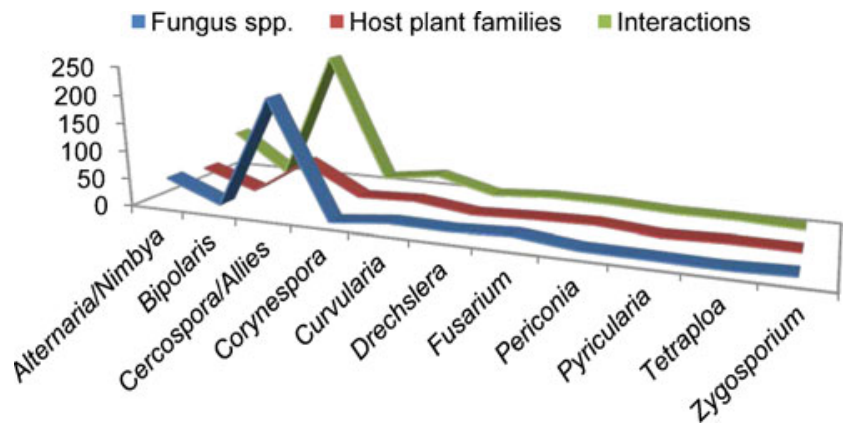

Fig. 3 Joint variations of fungi, plant families and their interactions 


\section{References}

Daub ME, Chung KR (2007) Cercosporin: a photoactivated toxin in plant disease. APSnet Feature Story February 2007. http://www. apsnet.org/publications/apsnetfeatures/Pages/Cercosporin.aspx. Accessed 17 September 2010

Daub ME, Chung KR (2009) Photoactivated perylenequinone toxins in plant pathogenesis. In: Deising $\mathrm{H}$ (ed) The Mycota V, plant relationships, 2nd edn. Springer, Berlin Heidelberg, pp 201-219

Daub ME, Ehrenshaft M (2000) The photoactivated cercospora toxin cercosporin: contributions to plant disease and fundamental biology. Annu Rev Phytopathol 38:461-90

Gessler NN, Aver'yanov AA, Belozerskaya TA (2007) Reactive oxygen species in regulation of fungal development. Biochem Mosc 72:1091-1109

Heiser I, Osswald W, Elstner EF (1998) The formation of reactive oxygen species by fungal and bacterial phytotoxins. Plant Physiol Biochem 36:703-713

Jacobson ES (2000) Pathogenic roles for fungal melanins. Clin Microbiol Rev 13:708-717

Jacobson ES, Hove E, Emery HS (1995) Antioxidant function of melanin in black fungi. Infect Immun 63:4944-4945
Ji J, Scott MP, Bhattacharyya MK (2006) Light is essential for degradation of ribulose-1,5-bisphosphate carboxylase-oxygenase large subunit during sudden death syndrome development in soybean. Plant Biol 8:597-605

Kawamura C, Moriwaki J, Kimura N, Fujita Y, Fuji S-I, Hirano T, Koizumi S, Tsuge T (1997) The melanin biosynthesis genes of Alternaria alternata can restore pathogenicity of the melanindeficient mutants of Magnaporthe grisea. Mol Plant-Microbe Interact 10:446-453

Kawamura C, Tsujimoto T, Tsuge T (1999) Targeted disruption of a Melanin biosynthesis gene affects conidial development and UV tolerance in the Japanese pear pathotype of Alternaria alternata. Mol Plant-Microbe Interact 12:59-63

Laemmlen F (2001) Alternaria diseases. ANR, Oakland

Nishimura S, Kohmoto K (1983) Host-specific toxins and chemical structures from Alternaria species. Annu Rev Phytopathol 21:87-116

Rotem J (1994) The genus Alternaria: biology, epidemiology, and pathogenicity. American Phytopathological Society, St. Paul

Thaung MM (1984) Some fungi of Cercospora complex from Burma. Mycotaxon 19:425-452

Thaung MM (2008) A list of hyphomycetes (and Agonomycetes) in Burma. Aust Mycol 27:149-172

Thomma BPHJ (2003) Pathogen profile Alternaria spp.: from general saprophyte to specific parasite. Mol Plant Pathol 4:225-236 